\title{
LA SUBJETIVIDAD DESCONCERTADA: PASCAL Y EL PENSAMIENTO TRÁGICO
}

\section{DISCONCERTED SUBJECTIVITY: PASCAL AND TRAGIC THOUGHT}

\author{
Carlos GÓmez SÁNCHEZ
}

UNED

Resumen: Tras señalar algunas razones de la vigencia de Pascal y analizar las líneas fundamentales de su contexto social e ideológico (con especial hincapié en el jansenismo y la polémica de Las provinciales), se consideran los problemas de edición y de interpretación de Pensées. Con posterioridad, se analizan algunos de sus principales núcleos temáticos, antropológicos y epistemológicos. Finalmente, se plantea una interpretación de le pari desde la que abordar las relaciones entre razón y religión, subrayando el lazo entre Pascal y Kant, que haría del primero (de manera similar a como Kant decía que, para él, Rousseau había sido el Newton de la moral) el Newton de la filosofía kantiana de la religión.

\section{Palabras Clave: Pascal, Kant, antropología, razón, religión.}

Aвstract: After indicating some reasons why Pascal continues to be valid and analyzing the main lines of his social and ideological context (with special emphasis on Jansenism and the polemic of The Provincial Letters), the problems for publishing and interpreting Pensées are considered. After this, some of the main thematic, anthropological, and epistemological nuclei are analyzed. Finally, an interpretation of le pari is set forth as a basis for discussing the relationship between reason and religion, underlining the link between Pascal and Kant, who made Pascal the Newton of the Kantian philosophy of religion (similarly to Kant's statement that Rousseau, for him, had been the Newton of morals). 
KeYwords: Pascal, Kant, anthropology, reason, religion

Para averiguar cuál es la historia que el problema de la ciencia y la conciencia ha tenido hasta ahora en el alma de los homini religiosi, sería necesario ser uno mismo tan profundo, estar tan herido, ser tan inmenso como lo fue y estuvo la conciencia intelectual de Pascal.

(F. Nietzsche, Más allá del bien y del mal).

\section{Vigencia de Pascal}

Al enfrentarnos con Pascal, no sabemos qué admirar más. Como estilista, no hay duda: ocupa uno de los primeros lugares de la literatura francesa y universal. Como científico, se alista en las primeras filas de un ejército de hombres que serían gigantes en cualquier otra compañía. Como filósofo, su tarea ha sido muy discutida y diversamente valorada: mientras unos encuentran en él una fecunda fuente de estímulos e inspiraciones que siempre sacudirán a los espíritus, para otros esos mismos estímulos son nocivos, aun cuando su presencia en el pensamiento y la literatura del mundo moderno hace difícil prescindir de ellos. En fin, como teólogo, su pensamiento es deudor de los límites de su tiempo, en el que no se había iniciado la crítica histórico-exegética de los textos bíblicos; pero esa crítica, por valiosa que sea, no anula los puntos de vista y posiciones del "teólogo" Pascal, que, inserto en una línea que va de Agustín a Karl Barth, a través de Lutero y Kierkegaard, aporta modulaciones propias muy a tener en cuenta en la evolución del pensamiento religioso moderno, sobre todo jansenista. Y esta última referencia nos abre a otra faceta en la que brilló con luz propia: su actividad de polemista, tal como revelan ante todo Las Provinciales.

Así, estilista, científico, filósofo, teólogo, polemista, el lector difícilmente permanecerá insensible ante su obra, aun cuando a muchos sea, con todo, su propia vida, el hombre Blaise Pascal, lo que les admira más. Nacido en ClermontFerrand el 19 de junio de 1623, tanto una como otra, la vida y la obra, tendrán un carácter trágico, bien subrayado en su día por el estudio Le Dieu caché de 
Lucien Goldmann (Goldmann, 1968), y que ha llevado recientemente a un autor como L. Kolakowski a sentenciar:

La religión de Pascal no estaba hecha a la medida de las necesidades de un cristiano decente normal; estaba hecha para la gente que podía soportar un suspense y una incertidumbre sin fin sobre la única cosa que realmente importa. Fue debidamente tratada con recelo. Independientemente de todas sus afirmaciones acerca de la felicidad de aquellos que 'han encontrado a Dios', era una religión para gente que no era feliz y estaba diseñada para hacerles aún más infelices (Kolakowski, 1996, 23) ${ }^{1}$.

Un juicio que convendría matizar, pues, por sombrías que sean muchas de sus consideraciones, por rigurosa -si es que no rigorista- que aparezca su actitud moral, y sin necesidad de tener que defender todos los puntos de vista sostenidos en Pensées, su lectura se hace imprescindible para comprender mucho de la condición humana, constituye una reserva de energía frente a la marea de banalidad que amenaza con soterrarla e incluso puede proporcionar la serenidad que siempre acompaña al acogimiento de nuestra condición, en vez de, escamoteándola, dejarla en la cuneta. Frente al hastío del pensamiento plano y la huida constante de sí, Pascal incita, casi acorrala al lector, para que tome la vida en sus manos, la sopese en su grandeza y en su miseria, y se decida respecto a lo que más importa (la posible trascendencia, la actitud moral), aun cuando la decisión de cada cual no tenga que seguir exactamente los derroteros por él marcados. Mas, aun cuando así fuera, no importa: siempre permanecerá el estremecimiento, el sacudir las conciencias del letargo, que era, con toda probabilidad, una de las cosas que más atrajeron de él, entre nosotros, a Unamuno, también agitador de conciencias y de espíritus. Su Vida de Don Quijote y Sancho comenzaba precisamente queriendo desencadenar "un delirio, un vértigo, una locura cualquiera" que sacudiera la modorra y el aletargamiento espiritual, "pues sólo los apasionados llevan a cabo obras verdaderamente duraderas y fecundas" y, sobre todo, esa obra de esperanza,

\footnotetext{
1 Recientemente, y en tono irónico, ha vuelto a insistir en ese punto de vista, al dedicarle una de las voces de su "Gran enciclopedia de la filosofía y las ciencias sociales", que consta sólo de tres páginas y está dedicada a aquellos que no quieren quemarse las pestańas: "Pascal: que admitas que eres un canalla y un imbécil, y tal vez logres la salvación (o no)", en Por qué tengo razón en todo (Kolakowski, 2007, 340). El título es de nuevo irónico: el original inglés provenía de la respuesta a E. Thompson a propósito de la consideración del marxismo, My Correct View on Everything, que luego encabeza el libro en el que esa larga carta se incluye. Más adelante veremos algunos matices del propio Kolakowski al respecto.
} 
que abandona los caminos trillados y se pone en marcha en busca del sepulcro de Dios, "para rescatarlo de creyentes e incrédulos, de ateos y deístas...y esperar allí...a que Dios resucite y nos salve de la nada" (Unamuno, 1966, 23 y 25).

Es cierto que no siempre se tiene por qué vivir la religión -si es que se vive de algún modo- con el dramatismo e incluso la angustia con que la vivieron Pascal y Unamuno (además de Kierkegaard, en esa misma filiación). Pero ninguno de ellos dejará que una vida que puede aspirar a "una arrebatadora plenitud" se consuma en el mercadillo de las nimiedades, lo que no tiene por qué suponer negar el espacio de la profanidad y la vida cotidiana. A los tres, y por lo pronto a Pascal, les tocó un destino trágico: precoz, tanto para desarrollar sus teorías como para morir, Pascal se desenvolvió entre la intensidad de una vida dedicada al pensamiento, la investigación, el desenmascaramiento psicológico y el ejercicio de la razón, y la fragilidad de su cuerpo, marcado por la aparición de sucesivas enfermedades, que comienzan el primer año y prosiguen hasta su muerte en 1662. Y es esa vida polémica, apasionada, a favor o en contra de personas o doctrinas, y las experiencias acumuladas en ella, la auténtica fuente inspiradora de sus escritos. Una vez más, fue Unamuno el que dejó dicho que la íntima biografía de los filósofos es la que más cosas nos explica.

El aparente olvido de Pascal, en determinadas épocas o movimientos, puede deberse, pues, a una vigorosa tendencia positivista, ajena desde luego a su espíritu, o a la cerrazón dogmática de buena parte de la escolástica católica, que se salvó aparentemente de los Pensamientos, como de tantas otras cosas de la Modernidad, simplemente por el hecho de haberlos ignorado (Aranguren, 1997, 585), aunque ellos han seguido ejerciendo su influjo al margen de esa teología o de esas corrientes filosóficas y han sembrado la inquietud en muy diversos medios, incluso ajenos a los estrictamente filosóficos o teológicos, como sucede en las películas de Roberto Rossellini, Blaise Pascal, o de Eric Rohmer, Ma nuit chez Maud.

Por otra parte, y como ocurre con otras obras, una comprensión adecuada de la suya requiere atender al contexto en el que surge y sin el cual fuera como si de una conversación sólo oyéramos lo que dice uno de los interlocutores. En el caso de Blaise Pascal, J. L. L. Aranguren ha indicado que su genialidad es ininteligible fuera de la gran familia humanista de la que procede, del escepticismo de Charron y de los ensayos de Montaigne, del racionalismo de Descartes y de la vida de los libertinos del XVII, del jansenismo y del jesuitismo, y, por supuesto, del grupo social al que perteneció y de su entorno inmediato, de su peculiar 
formación. Y así, aunque sea brevemente, hemos de comenzar atendiendo a alguno de esos factores.

\section{El contexto social e ideológico: el jansenismo}

\subsection{El jansenismo en la controversia teológica cristiana: Pablo, Agustín, Lutero}

Se utiliza el término "jansenismo" para referirse a los seguidores de la doctrina de Jansenio, monje belga, cuya obra Augustinus, publicada en 1640, retomaba cuestiones abordadas por san Agustín, debatía los problemas de la libertad y la gracia, y proponía una moral rigurosa, retornando al estilo y la vida de la antigüedad cristiana. El jansenismo tuvo su principal centro de difusión en la abadía francesa de Port-Royal, provocó importantes reacciones y fue perseguido política y religiosamente.

Lucien Goldmann, en su ya citado estudio Le Dieu caché, propone una explicación sociológica: el jansenismo estaba vinculado a una determinada estructura económica y social, la noblesse de robe, la nobleza de toga y los oficiales que, en el tránsito de una monarquía moderada a la monarquía absoluta de Luis XIII y de Richelieu, perdieron poder. Este desplazamiento les llevó a acoger de buen grado una ideología que propugnaba el rechazo de un mundo corrupto como condición de la salvación y se oponía tanto al absolutismo religioso de Roma como al absolutismo político de la nueva monarquía francesa. Nos encontraríamos, por tanto, con una situación social propicia para la difusión de la teología jansenista de la debilidad y miseria del hombre, teología que se adapta a las conveniencias de un grupo social en decadencia. De ahí la importancia que el fenómeno alcanzó en Francia y el peligro que en él se vio.

Sin negar la relevancia de esos condicionamientos, muchos autores se han negado

a una reducción sociologista del jansenismo. La explicación sociológica, como recuerda Aranguren, "ayuda a entender el porqué de la trascendencia social, de otro modo a todas luces desmesurada, lograda en Francia por un libro teológico de segundo orden" (Aranguren, 1997, 587), pero no resuelve los problemas planteados, por cuanto en ellos se debaten asimismo cuestiones teológicas autónomas. Así, Jean Delumeau, en su estudio El catolicismo de Lutero a Voltaire 
(Delumeau, 1973), estima que, como sucede en la Reforma protestante, hay motivos filosóficos, teológicos y de concepción del mundo, que no afectan sólo a las ideas, sino también a los sentimientos y las actitudes, y que no pueden ser disueltos por una explicación reduccionista que los considere simples epifenómenos. Lo que se discute, en efecto, es el papel de la libertad humana y su posible conjugación con la gracia divina en orden a la salvación del hombre y el sentido de su vida, polémica que, con otros perfiles y acentos, ya estaba presente en la controversia de Agustín con Pelagio: mientras que para éste, el hombre no está predestinado, sino que puede conseguir la salvación, merecerla por su propio esfuerzo moral, una determinada interpretación de algunos textos de san Pablo, y sobre todo del primer capítulo de la Carta a los Romanos, donde Pablo afirma que "el justo vivirá por la fe", insistirá en la necesidad de la gracia divina para el logro de la perfección humana, pues la corrupción del hombre, tras el pecado original, le incapacita para la realización efectiva del bien sin el auxilio de Dios.

Esta controversia se reavivó en tiempos de la Reforma protestante: la pretensión de conquistar el cielo a través de las obras humanas era a ojos de Lutero la expresión del mayor extravío del hombre, que olvidaba su naturaleza caída; al estimar merecer a Dios y alzarse hasta Él sólo con su propio esfuerzo no hacía sino endiosarse a sí mismo y alejarse de su verdadera humanidad. Como sentencia alguna vez: "Los hombres creen ser amados por ser bellos, cuando en realidad son bellos por ser amados" (Lutero, 1977, 85). La venta de las indulgencias, aunque la Iglesia insistiera en la necesidad de la buena disposición interior, ponía de relieve ese estado de cosas llevado a la caricatura, como si la vida eterna pudiera lograrse sólo por obras extrínsecas e incluso puramente monetarias; como si se pudiera, por así decirlo, comprar a Dios. Ahora bien, insistirá Lutero: sólo Dios salva. No hay posibilidad de aproximación entre la infinitud de Dios y la finitud de la criatura humana, sino es por la iniciativa de Dios mismo. Esta situación no exime de la necesidad de obrar bien moralmente. El error estriba en creer que con las buenas obras uno puede alcanzar a Dios; desde ese momento, es el hombre mismo el que pretende convertirse en Dios y la acción moral se torna en su contrario. Su dura experiencia ascética, su drama personal le puso bien de manifiesto el encierro del hombre: el homo incurvatus in se no sale de sí mismo, sino que, enorgulleciéndose de su buen obrar, se aferra más profundamente a su cerrazón

2 Entre los muchos estudios sobre Lutero, siguen siendo de interés y magníficamente escritos los del gran historiador francés, fundador de Annales, Lucien Febvre, Martin Lutero: un destino y, en un contexto más amplio, Erasmo, la Contrarreforma y el espiritu moderno (Febvre, 1975 y 1970). 
espiritual. El hombre haría bien en abandonar sus fantasías de omnipotencia y poder sobre los demás, pues en el "Dios crucificado", en la muerte de Jesús en la cruz, no se revela el Dios atronador del poder, al que el hombre quisiera alzarse para escapar de su debilidad, sino la "impotencia del amor", que puede transformarnos hasta provocar una "esperanza contra toda esperanza". Es por eso por lo que, como el mismo Pablo manifiesta en 1Cor. 1, y el propio Lutero no dejará de recordar, no ha elegido Dios a los ricos, ni a los poderosos, ni a los sabios, ni siquiera a los honrados satisfechos de sí mismos, sino que ha preferido más bien a los pobres, a los débiles, a los locos y extraviados, y a los pecadores, no para exaltar la debilidad, la locura o la maldad, sino para que nadie piense que se puede bastar a sí mismo, sino que, sean cuales sean sus dones naturales o morales, "ninguno se gloríe de sí mismo y el que se gloríe que se gloríe en el Señor".

Es cierto que esta posición, al tratar de impedir la deificación del hombre, puede subrayar tanto su corrupción, que arruine el ímpetu moral humano o lo agoste de tal modo que el hombre aparezca como una marioneta ante los designios inexcrutables de Dios. Así sucederá en la doctrina de la predestinación expresamente formulada por la rama calvinista de la Reforma.

Ante esta situación, la Iglesia romana vio siempre con desconfianza al agustinismo, no en lo que pudiera tener de herencia común para los cristianos, sino en el específico momento en que sus tesis parecían aproximarse peligrosamente a la doctrina protestante de la predestinación. Sin dejar de negar que es Dios el que salva, la Iglesia tendió a subrayar el papel y la importancia de las obras y la vida moral del hombre en la economía de la salvación. Una disputa a fin de cuentas estéril, si así se quiere considerar, por cuanto ambas doctrinas venían a mantener al cabo lo mismo, aun cuando es cierto que desde diferentes talantes. Y en las discusiones filosóficas y teológicas, los matices, los subrayados, los acentos, no son minucias que se puedan despreciar, sino que, en muchas ocasiones, constituyen el centro de la cuestión -sin que ello justifique, desde luego, que, en función de esas cuestiones, se pueda llegar a las atrocidades a que católicos y protestantes se entregaron en las interminables guerras de religión que asolaron la Europa moderna. 


\subsection{La polémica del libre albedrío y la vida moral}

Mas lo cierto es que la polémica acerca del libre albedrío iba a ocupar buena parte del escenario filosófico-teológico de la primera modernidad, hasta convertirse, como indica Delumeau, en el principal y dramático problema de la religión europea "durante el período comprendido entre la época de Lutero y Voltaire” (Delumeau, 1973, 120). En 1547, la Iglesia católica romana afirmó la posibilidad del libre albedrío y, al mismo tiempo, la necesidad de la gracia, sin definir la relación entre ambos términos y la convivencia entre posturas que, en principio, podrían parecer contradictorias. Y así, la polémica proseguirá, dentro del propio catolicismo, en la oposición entre dominicos -que siguen ante todo a santo Tomás, al poner el acento sobre la gracia, previa a todo libre asentimiento, por sí misma eficaz, tal como lo defiende sobre todo D. Báńez- y jesuitas -que ponen el acento en la libre voluntad, la cual daría paso con su asentimiento a la eficacia de la gracia antecedente; es decir, Dios concede a todos los hombres una gracia suficiente para salvarse, pero depende de ellos y de sus obras el conseguirlo o no, el que esa gracia de Dios, que es en definitiva la que salva, resulte o no "eficaz": es la posición del "molinismo" jesuítico, así denominado por el nombre de su principal valedor, L. de Molina-. Es en estas circunstancias en las que se desarrolló, primero en la Universidad de Lovaina, en Bélgica, y luego en la abadía francesa de Port-Royal, cercana a Versalles y que contaba con una filial en París, el jansenismo, cuyos principales representantes (el obispo Jansenio, el abad Saint-Cyran, Angélique Arnauld, abadesa de Port-Royal, y su hermano menor, Antoine Arnauld), defenderán la gratuidad de la fe, frente al molinismo jesuítico.

Esa polémica acerca del poder de la libertad humana se veía redoblada por las diferentes maneras de concebir la vida moral del hombre. Y, curiosamente, no van a ser los jansenistas, que desconfiaban de ese poder, los menos exigentes, sino que, al contrario, pese a la señalada insuficiencia del esfuerzo moral para alcanzar la salvación, serán ellos los más rigurosos en lo que a ideales morales y disciplinarios se refiere: los jansenistas se opondrán, por ejemplo, al arrenpentimiento por atrición (en realidad, no hay pesar por el mal realizado o deseado, sino sólo a causa del temor a la condenación), incluso cuando fuera unido al sacramento de la penitencia, pues la simple atrición no libera al hombre del poder del pecado, sino que, al contrario, le vuelve más culpable. Pascal arremeterá en su décima "provincial" contra semejante posición, según la cual, ironiza, "se puede conseguir la salvación sin haber amado a Dios jamás en la vida”. Los jansenistas fueron así partidarios del arrenpentimiento por contrición, por verdadero dolor de corazón de haberse apartado de Dios y del espíritu universal, anteponiendo 
el propio yo al amor. Aunque el concilio de Trento había condenado la postura luterana acerca de la imperfección atricista, no se detuvo en los debates entre unos y otros, y, rechazando la alternativa "o todo o nada", la Iglesia católica seguía dando la absolución a los penitentes desprovistos de contrición perfecta, viniendo a entender algo así como que, si no perfectamente arrepentidos, la confesión suponía al menos el arrepentimiento de no arrepentirse.

Los jansenistas se opondrán asimismo a la comunión frecuente, pues aunque los hombres deberían hallarse en estado de recibir al Señor todos los días, esa situación de relativa santidad, contrariada incesantemente por la concupiscencia y el amor de sí, es difícil de lograr, reconociendo lo cual, los hombres harían bien al privarse de la comunión, a fin de evitar la rutina, que hace degenerar el sacramento en ritual automatizado y exento de sentido. El período de espera es una especie de noviciado, a lo largo del cual el hombre debe prepararse, en expectación y conversión, para una vida purificada y renovada. En 1643, Antoine Arnauld escribió un tratado, De la fréquente communion, en el que se eleva contra "los seductores de almas", es decir, los jesuitas, capaces de todas las dobleces y de una casuística que defienda sus intereses, de acuerdo con los cuales, cualquier conducta queda finalmente justificada y permitida si les resulta conveniente. Y será contra esa moral relajada y laxa contra la que el jansenismo se alce y, como veremos, Pascal con ellos.

Aun tratándose, pues, de una polémica teológica y moral, el problema del jansenismo trascendió socialmente. Reacción, ante todo, contra los excesos del jesuitismo, esa trascendencia social no podía evitarse, pues detrás de la complejidad de los argumentos se hallaban cuestiones que afectaban a todo ser humano, máxime en una época teńida de religiosidad, pues, tal como subraya Delumeau: "¿Acaso puede prohibirse a los hombres que se pregunten a sí mismos si están actuando por propia voluntad, o si sus actos son dirigidos desde el exterior?" (Ibid., 121). La controversia acabó por extenderse a los salones y el teatro: Pierre Corneille, el creador de la tragedia francesa, era de orientación molinista; Jean Baptiste Racine, que eleva el teatro clásico francés a su máxima expresión, educado como huérfano en Port-Royal y que también allí quiso ser enterrado, partidario del jansenismo.

Ambivalente en su relación con la Modernidad, según ha puesto de manifiesto Aranguren -si por una parte agrupa a muchos miembros de la alta burguesía, que papel tan activo había de desarrollar en el mundo moderno, y representa la rebeldía y el talante "liberal" frente a la presión exterior, por otro, al preconizar 
la vuelta a la antigua moralidad cristiana y el refugio en la privacidad, se opone a la mundanización (Aranguren, 1997, 590)-, el jansenismo fue perseguido por la monarquía absoluta, recelosa de un movimiento que daba tantas alas a los fueros del individuo, y por la Iglesia romana, obsesionada con cortar de raíz cualquier brote sospechoso de heterodoxia. Finalmente, cinco de las proposiciones básicas del "credo" jansenista fueron condenadas por Inocencio X en 1653. Pero con ello no se acabó con un espíritu que, de una u otra forma, habría de prolongarse y renacer. Respecto a la condena misma, los jansenistas optaron por reconocer la heterodoxia de las proposiciones (y, por tanto, la competencia del Papa en la cuestión "de derecho"), pero negaron que esas proposiciones se encontraran en Jansenio (y en esa cuestión "de hecho" el Papa no decide). Poco después, los jesuitas consiguieron que la Sorbona condenara a Antoine Arnauld en 1656. Pero, pese a los adversarios que despertaba, el jansenismo también canalizó a su favor la aversión que gran número de devotos, laicos o eclesiásticos, experimentaban por el laxismo jesuítico. Entre ellos, se encontraba el arma bien afilada de la pluma de Pascal.

\subsection{Pascal y el jansenismo: Lettres provinciales}

En contacto con el medio jansenista desde la época de lo que se ha llamado su "primera conversión", será a partir de 1654 cuando Pascal entre en estrecho contacto con el convento de Port-Royal, donde residía su hermana Jacqueline, y, a raíz de la condena de Arnauld, decide terciar en la polémica y publica en 1656 sus Lettres provinciales, sus "Cartas a un [supuesto] amigo de provincias", con las que inventa un nuevo género literario, el panfleto, capaz de tratar intrincadas cuestiones en un estilo irónico, agresivo, pulido, que alcanzará gran resonancia social. Devoradas por el público, las Provinciales prestan a los jansenistas el apoyo más notable que podían esperar. Las tres primeras se dirigen contra la Sorbona con ánimo de desenmascarar a los responsables del proceso de Arnauld. La reacción de los jesuitas es diligente: los impresores de la obra son perseguidos o encarcelados, las aulas de Port-Royal clausuradas, en Roma presionan para conseguir una condena definitiva. Y, entonces, Pascal cambia el blanco: en las Provinciales "morales" (de la $4^{\mathrm{a}}$ a la 16a ambas incluidas), centrando sus críticas en la Somme des péchés del P. Bauny y en el Liber theologiae moralis, en el que en 1644 el P. Escobar había compilado las máximas de 24 casuistas de la Compañía de Jesús, ataca la moral laxa e hipócrita de los jesuitas, su afán de poder, su espíritu de cuerpo, su persecución de fines muy temporales con medios presuntamente espirituales, su habilidad para diestras calumnias que se apoyan en medias verdades, su propuesta de "una vida sin molestias y el cielo a bajo precio", y el que 
justificaran, según sus conveniencias, las peores acciones mediante el método de las "opiniones probables". Es posible que Pascal generalizara en exceso. Pero, si no todos los jesuitas, el espíritu "jesuítico", que, además de relativo a la Compañía de Jesús o a un estilo artístico -el inaugurado precisamente por la Iglesia del Gesù, en Roma-, ha venido a convertirse también, según figura en cualquier buen diccionario, en sinónimo de hipócrita -con razón o sin ella, y yo diría que más bien con ella, aunque quizá no con toda ella- quedó profundamente desacreditado.

De todos modos, las cosas no iban a ponerse bien ni para los jansenistas ni para Pascal: el Papa Alejandro VII ratificará la bula de su predecesor Inocencio $\mathrm{X}$, condenando algunas proposiciones de Jansenio, y en 1657 las Provinciales son incluidas en el Índice, condenadas también por el Consejo de Estado de París y quemadas públicamente el 14 de octubre de 1660. Con la distinción, a la que ya hemos hecho referencia, entre cuestiones de hecho y de derecho, Port-Royal trató de resistir. Jacqueline Pascal escribió incluso una altiva carta, digna de su hábil hermano, en la que abogaba por negarse a firmar la condena, arguyendo que si los obispos no tenían ánimo sino de muchachas, debían las muchachas tener ánimo para oficiar de obispos. Pero la resistencia será en vano: Jacqueline acaba por firmar, por consejo de Arnauld, que hace otro tanto; el propio Racine critica duramente a Port-Royal, la polémica se hace cada vez más sectaria y, finalmente, el "Rey Sol", de acuerdo en esto con el Papa, le asesta el golpe definitivo: destierra a Arnauld y a su compañero de lucha Pascasio Quesnel, y hace derribar los muros de Port-Royal, aun cuando las discusiones continuaron durante mucho tiempo. El espíritu jansenista influirá, en lo referente a las relaciones entre el Estado y la Iglesia, en la "Constitución civil" de la época de la Revolución, defendiendo una cierta autonomía de la nación. Y el jansenismo será, hasta hoy, sinónimo de quien pretende ser rigorista-protestante y católico a un tiempo; o, si se quiere, y por decirlo muy sucintamente, una forma de reivindicar el talante o el espíritu del protestantismo en el seno del catolicismo.

Pascal, por su parte, se oponía a todo compromiso. Si Jansenio, y con él Agustín, tenía razón, el Papa y la Iglesia actual no la tenían. Estaba incluso dispuesto al enfrentamiento público con Roma y los obispos, como se manifiesta en su escrito Sur l'obéissance due à l'Église et au pape. Pero el hecho de que la mayoría de sus amigos acabaran remitiéndose a la infalibilidad de la Iglesia le decepcionó y, entonces, se retiró para concentrarse en su obra Sobre la verdad de la religión cristiana, de la que nos han llegado esos fragmentos que son los Pensées. 
Antes de entrar en el estudio de algunas de sus líneas principales, podemos, al final de este apartado, y tras lo visto, preguntarnos: ¿fue Pascal jansenista? Creo que la respuesta se debe matizar: si por jansenista se entiende compartir cierta concepción del hombre y del mundo y ciertas verdades teológicas defendidas por Port-Royal, y que aquí hemos querido evocar, no cabe duda de que Pascal lo fue. Pero esa proximidad no debe ocultar, sin embargo, otras diferencias, bien señaladas por Alicia Villar, pues

Si Pascal compartía las concepciones jansenistas, ¿cómo puede conjugar su visión pesimista del hombre y del mundo con una vida y una obra que parecen describir el ideal renacentista del hombre universal que sabe de todo? [...]. Si piensa que sólo tiene sentido buscar a Dios y que hay que retirarse del mundo, ¿por qué nunca abandona la actividad científica? (Villar, 1987, 55).

Quizá Pascal acabó por pensar y por intentar realizar ese ideal trágico, pero no exento de grandeza, de "vivir en el mundo, como si no viviéramos en él"; es decir, entregarse al trabajo en el mundo, sin espíritu mundano, y vivir lo eterno desde la temporalidad. No cabe duda de que su vida y su obra revelan entonces un grandioso testimonio de la limítrofe condición humana: desde su contingencia, incertidumbre y finitud, el hombre eleva sin embargo pretensiones de incondicionalidad, dondequiera que alguien habla realmente de moral, y no simplemente de técnica o de estrategia, esto es, cada vez que apela a un imperativo ético, como más tarde formularía con precisión Kant; que es quizá asimismo por lo que -en la prolongación de esa saga- Wittgenstein dejó dicho que si alguna vez alguien escribiera un libro de ética, que realmente tratase de ética, ese libro haría estallar, como en una explosión, todos los demás libros del mundo. Y esa incondicionalidad franquea la puerta a lo Absoluto, al menos como problema. Para hacerse cargo, entonces, de las tensiones que la finitud y la posible Trascendencia fraguan en el hombre, habría quizá que ser tan inmenso, estar tan herido -para decirlo con las palabras del motto inicial de Nietzsche-, como lo fue y lo estuvo la conciencia intelectual de Pascal. No todos las viven con su pathos trágico, ni quizá sea necesario hacerlo así. Pero tampoco todos, ni mucho menos, saben afrontarlas con tal radicalidad.

En sus últimos días, que no queremos dejar de evocar por manifestar de nuevo ese carácter tenso entre extremos que preside su actitud, Pascal, cada vez más debilitado por una enfermedad sin firme diagnóstico, sometido a sangrías y purgas inútiles y a un montón de medicamentos ineficaces, además de a la severa disciplina que se autoimponía, tuvo fuerzas aún para una nueva faceta de 
su actividad: organiza la primera compañía de transportes de París, pero no se queda con los beneficios, sino que los lega a los hospitales de la ciudad y a los de Clermont-Ferrand. Poco después, hace el inventario de sus bienes, decide repartirlos entre los pobres, y acoge en su casa a una familia necesitada y enferma. Cuando agoniza, el párroco le lleva la comunión, pero el cura habrá de justificarse luego ante el arzobispo de París, severo antijansenista, ante el que asegura que Pascal había roto con Port-Royal, testimonio que el arzobispo no dudará en exhibir triunfalmente. En cuanto a Pascal mismo, siempre se mantuvo persuadido de la concordancia de su fe personal con la de la Iglesia, aunque en sus últimos avatares esa fe eclesiástica pareciera definirse contra la de su conciencia. Él creyó ser fiel a ambos reclamos -tan importantes para él, por enfrentados que se encontrasen- con su actitud. Sus últimas palabras fueron: " $\mathrm{Q} Q u e$ Dios no me abandone jamás!”. Murió el 9 de agosto de 1662, recién cumplidos los 39 años.

\section{Pensées}

\subsection{Problemas de edición}

Como hemos indicado, Pascal no pudo dar fin a su proyectada apología, Sobre la verdad de la religión cristiana, y en su lugar lo que tenemos es el conjunto de fragmentos agrupados bajo el nombre de Pensamientos. Ahora bien, esos "pensamientos" son de muy diverso carácter y extensión: algunos parecen sólo apuntes que han de desarrollarse, mientras que otros conocen un tratamiento más pormenorizado; tampoco se sabe bien el orden en el que han de disponerse, si es que alguno tuvieran. La primera edición que se hizo de los mismos, denominada edición de Port-Royal, de 1670, tan sólo ocho años después de la muerte de su autor, apareció con el título de Pensamientos del señor Pascal sobre la religión y algunos otros temas, y ya entonces se discutió la ordenación de los mismos: la familia prefería presentarlos tal como se habían encontrado, cosidos en distintos legajos, aunque al final predominó la tendencia, defendida por A. Arnauld, de agruparlos en un orden lógico, sin preocuparse por el posible plan de Pascal. De todas formas, la familia Périer, emparentada con la de Pascal, salvó los originales e hicieron copias, encontrándose hoy aquéllos y dos de éstas en la Biblioteca Nacional de París.

La edición de Port-Royal triunfó hasta 1776, año en el que apareció otra, debida a Condorcet, que rompe con la clasificación de Port-Royal y distribuye los fragmentos en dos grandes grupos: pensamientos filosóficos y pensamientos 
religiosos. Durante el siglo XIX, el interés por Pascal, unido a la interpretación romántica del mismo, se acrecienta y, a fines de esa centuria, en 1897, se publica una nueva edición, debida a L. Brunschvicg, que renuncia a reconstituir el plan de Pascal y agrupa los fragmentos en el orden más racional posible. Es una edición a la que todavía hoy se sigue haciendo referencia, y otras posteriores, como la de Chevalier, no lograron eclipsar su éxito.

A mediados del siglo pasado, en 1942, Zacharie Tourner realizó una edición paleográfica, adoptando la clasificación de la copia de la Biblioteca Nacional de París, lo que estimuló estudios posteriores, en particular los de Louis Lafuma. A él se debe la edición considerada hasta el momento como más cuidada (Pascal, 1963), en espera de la realizada por Jean Mesnard en la gran Edición del Tricentenario, y de la que se prevén 7 volúmenes -los Pensées figurarán en el último- (Pascal, 1964-1992), de los que hasta ahora han aparecido sólo cuatro. En diversos estudios preliminares (Mesanrd, 1973), Mesnard ha indicado que, aun sirviéndose tanto de los originales como de investigaciones anteriores, y aunque limitada, la interpretación del editor seguirá desempeñando un papel. Según su criterio, ciertos fragmentos que ediciones anteriores tendían a agrupar en torno a algunos temas centrales -miseria del hombre, Dios oculto- se reparten a lo largo de la obra y apoyan razonamientos diversos. En líneas generales, Mesnard distingue dos grandes partes: la primera trataría de mostrar que la religión es venerable, porque ha conocido bien al hombre, y amable, porque promete el verdadero bien; la segunda, trataría de mostrar que es verdadera, aunque sólo hasta donde ello es posible, porque en ningún caso se trataría de eximir de la fe.

En castellano, se cuenta con diversas ediciones y traducciones. A la de Eugenio d'Ors (Pascal, 1976), se sumó una traducción parcial de Xavier Zubiri, siguiendo la edición Brunschvicg (Pascal, 1962), y luego se han sucedido otras, entre las cuales pueden recordarse la de Carlos R. Dampierre (Pascal, 1981a) y la de J. Llansó (Pascal, 1981b), que sigue la edición de L. Lafuma. Recientemente, han aparecido las Obras de Pascal, editadas por Gredos, utilizando diversas traducciones y con estudio preliminar de Alicia Villar (Pascal, 2012), para la cual "la diversidad de criterios seguidos en las distintas ediciones a lo largo de la historia muestra que, en el caso de esta obra, el orden puede alterar definitivamente el producto, ya que el lector que se adentra en los Pensamientos tiene una impresión muy distinta según utilice una u otra. Escéptico o místico, misántropo o humanista, romántico o racionalista, ortodoxo o herético han sido algunas de las calificaciones de sus intérpretes" (Villar, 2012, LXXIII-LXXIV). Nosotros seguiremos preferentemente la edición de Lafuma en traducción de 
Llansó (si bien, en ocasiones, ofreceré la de X. Zubiri, por gustarme más), aunque señalando también la correspondencia con la ya clásica de Brunschvicg, de manera que, en las citas de Pensées, el primero de los números remite a Lafuma y el segundo a Brunschvicg.

\subsection{Problemas de interpretación}

Con lo que hemos dicho, podemos hacernos una idea de la dificultad de interpretar los Pensamientos de Pascal, pues, a los obstáculos habituales, se agrega el carácter fragmentario y el orden desconocido (presuponiendo que hubiera alguno) de esos fragmentos, que, por lo demás, no sabemos si estaban llamados a constituir o no una obra sistemática. Así, el formidable influjo de la obra, al que al comienzo nos referíamos, su vigencia durante más de tres siglos, se apoya sin duda en su reconocida capacidad estilística, que le ha convertido, más allá de los acuerdos o desacuerdos doctrinales, en una permanente referencia literaria. Pero esa facilidad de expresión no conlleva una similar facilidad de comprensión. En su artículo "La trivialidad de Pascal" (en donde el término "trivialidad" está tomado en el sentido hacer vibrar, de sacar punta, a lo aparentemente sabido y vulgar), Kolakowski lo exponía con precisión:

De los "grandes filósofos", a ninguno se le lee con tanta facilidad y con tal sentimiento de comprensión inmediata como a Pascal; y, sin embargo, ninguno suscita tan enormes dificultades de interpretación. En Pascal, todo es claro, y no obstante todo es ambiguo (Koakowski, 1971, 56).

Y también Jean Mesnard, el gran especialista pascaliano, ha indicado cómo el carácter fragmentario facilita la rápida intuición, pero también el equívoco:

Los Pensamientos se presentan bajo la forma de un millar de fragmentos, que ora nos confían una reflexión cogida al vuelo, ora constituyen un fragmento elaborado de la futura obra. Este estado incompleto nos permite entrar como en la intimidad del autor y confiere a la obra un carácter único y singularmente atractivo. Pero también favorece enormemente la arbitrariedad (Mesnard, 1973, 132).

Teniendo en cuenta todas esas dificultades, intentaré indicar aquí algunas líneas básicas que pueden destacarse en Pensées, cuyo carácter fragmentario y, tal como lo encontramos al menos, asistemático, no les resta ni riqueza ni rigor. 


\section{La condición humana}

\subsection{Desproporción}

\subsubsection{El hombre, entre dos abismos}

Quizá la primera nota que destaque en la descripción pascaliana del hombre, sea la desproporción en la que éste se encuentra sumido. Desproporción respecto al universo, este carácter de nada frente al todo, de insignificancia frente al infinito que le envuelve, quizá siempre perceptible, se vuelve mucho más agudo ante los descubrimientos de la Revolución Científica moderna. En la Antigüedad clásica, el hombre suponía un motivo de asombro para el propio hombre, tal como manifestaba con claridad el coro en la Antígona de Sófocles:

Muchas cosas asombrosas existen y, con todo, nada más asombroso que el hombre [...que], poseyendo una habilidad superior a lo que se pueda uno imaginar, encamina la destreza para ingeniar recursos unas veces al bien, otras al mal (Sófocles, 1992, 332-333).

Y el asombro ante el universo y uno mismo era para Aristóteles, como es sabido y tal como figura en las primeras líneas de su Metafísica, el principal resorte del filosofar: "En efecto, los hombres -ahora y desde el principio- empezaron a filosofar al quedarse maravillados ante algo" (Aristóteles, 1994, 76). Con todo, en la visión clásica, el hombre se encontraba ante un mundo misterioso, pero más o menos bien ordenado y limitado. Ahora, con la revolución copernicana, el hombre alcanza un nuevo sentimiento de poder, convencido de los logros de sus nuevas explicaciones del mundo en torno. Pero éste se le muestra mucho más amplio y huidizo. De centro del universo, como lo era en la concepción geocéntrica ptolemaica, el hombre se ve desplazado a una diminuta partícula de un minúsculo planeta. Y así, el sentimiento de poder se dobla de un sentimiento de pérdida y de vértigo, pues la contemplación del cielo estrellado, no sólo provoca admiración, sino asimismo horror, conciencia de la propia insignificancia, en la que quisiéramos no pensar, pero que se nos impone ante la "belleza espantosa" del universo. Es por ello por lo que Pascal apostillará: "El silencio eterno de los espacios infinitos me espanta” $(201,206)$.

Pero si el hombre es una nada frente al infinito del universo, es a la vez un todo frente a lo infinitamente pequeño (no olvidemos que Pascal contribuyó de manera muy notable al desarrollo del cálculo infinitesimal), en donde también 
nos perdemos en proporciones cada vez menores y que, sin embargo, y pese a estar ahora tan cercanas, tampoco podemos alcanzar. Cualquier cuerpo, por mínimo que sea, puede descomponerse en unidades cada vez menores, que provocan de nuevo, por el otro extremo de la cuestión, nuestra admiración y nuestra inquietud:

¿Quién no se admirará de que nuestro cuerpo, que antes no era perceptible en el universo, imperceptible él mismo en el seno del todo, sea ahora un coloso, un mundo, o más bien un todo respecto de esa nada a la que no se puede llegar? $(199,72)$.

Así, tendido entre lo infinitamente grande y lo infinitamente pequeño, el hombre se encuentra sometido a extremos que le conciernen pero que desconoce: ¿Qué es el hombre en la naturaleza? Una nada frente al infinito, un todo frente a la nada, un medio entre nada y todo $(199,72)$. Y es ese verse afectado por lo que le huye, lo que constituye uno de los factores radicales de su trágica condición, abocada a cosas tan inesquivables como inexcrutables.

Pero si el universo en el que se encuentra inmerso se le escapa, otro tanto sucede con su propio ser: por mucho que llegue a saber, no puede alcanzar a comprender las condiciones básicas de su existencia. Las grandes preguntas ¿¿de dónde? y ¿adónde?, ¿por qué ahora y aquí?, ¿para qué?, se le plantean de forma inexorable, pero de nuevo insolubles, hasta el punto de que, estando siempre cabe sí, resulta, no obstante, extraño para sí mismo. ¡Curioso ser, capaz de preguntarse quién es, mas incapaz de contestarse!:

No sé quién me ha puesto en el mundo, ni qué es el mundo, ni qué soy yo; me hallo en una terrible ignorancia de todas estas cosas. No sé lo que es mi cuerpo, qué mis sentidos, qué mi alma, ni qué es esa misma parte de mi yo que piensa lo que digo, que reflexiona sobre todo y sobre sí misma, y no se conoce a sí misma mejor que al resto $(427,194)$.

Mas, a pesar de su terrible ignorancia de todo lo que más le importa, la paradójica condición del hombre se pone de manifiesto, en que, pese a todo, él sabe más que todo lo que le rodea, y eso le da una centralidad que contradice su insignificancia. Y es este carácter de "centro descentrado", de ser más que todo lo que le supera, lo que hace muy próxima la concepción pascaliana del hombre a la que más tarde sostendrá Kant. 
4.1.2. Pascal, el Newton de la filosofía kantiana de la religión: sometimiento sensible y grandeza moral

No será la única vez que tendremos ocasión de señalar tal proximidad, pero, tras todos los anteriormente recordados, se apunta otro gran texto que no podía dejar de venirnos a la mente cuando los evocábamos. A saber, aquel famoso pasaje, en el que en el primer párrafo de los tres de que consta la "Conclusión" de la Crítica de la razón práctica, y tras sus pormenorizados y, a veces, complejos desarrollos, Kant quiere ofrecer sintéticamente un balance de su visión del hombre. Texto que no por muchas veces recordado podemos dejar ahora de citar. Y dice en él Kant:

Dos cosas llenan el ánimo de admiración y respeto, siempre nuevos y crecientes, cuanto con más frecuencia se ocupa de ellas la reflexión: el cielo estrellado sobre mi y la ley moral en mí. Ambas cosas no he de buscarlas y como conjeturarlas, cual si estuvieran envueltas en oscuridades, en lo trascendente fuera de mi horizonte; ante mí las veo y las enlazo inmediatamente con la consciencia de mi existencia [...]. El primer espectáculo de una innumerable multitud de mundos aniquila, por decirlo así, mi importancia como criatura animal que tiene que devolver al planeta (un mero punto en el universo) la materia de que fue hecho después de haber sido provisto (no se sabe cómo), por un corto tiempo, de fuerza vital. El segundo, en cambio, eleva mi valor como inteligencia infinitamente por medio de mi personalidad, en la cual la ley moral me descubre una vida independiente de la animalidad y aun de todo el mundo sensible, al menos en cuanto se puede inferir de la determinación conforme a un fin que recibe mi existencia por esa ley que no está limitada a condiciones y límites de esta vida, sino que va a lo infinito (Kant, 1972, 201).

¿Cómo no ver un claro precedente de esa concepción en dos hermosísimos pensamientos de Pascal, en los que, aun sin el desarrollo explicativo al que Kant procede, se expresa sintéticamente -y con una retórica estilística superior- una visión similar? El primero indica de manera muy breve y efectista, gracias a la fuerza de la antítesis: "Por el espacio inmenso, el universo me envuelve y me devora como un punto; por el pensamiento le envuelvo yo a él" (113,348).

El segundo retoma el tema de la "cańa pensante", desarrollado asimismo en otros pasajes, para poner de manifiesto que, aunque el hombre sea el ser más 
débil de la naturaleza, supera a todo el universo, puesto que él es el único capaz de pensar y de saber, mientras que el universo no sabe nada:

El hombre no es más que una caña, la más débil de la naturaleza, pero es una caña pensante. No hace falta que el universo entero se arme para aplastarle: un vapor, una gota de agua le pueden matar. Pero aun cuando el universo le aplastara, el hombre sería todavía más noble que lo que le mata, porque sabe que muere y la ventaja que el universo tiene sobre él; el universo en cambio no sabe nada $(200,347)$.

No obstante, el parentesco entre los textos no debe ocultar una importante diferencia: Para Pascal, lo que distancia al hombre del resto de la naturaleza y le otorga su superioridad respecto a ella es el pensamiento: es por el pensamiento por lo que el hombre es capaz de envolver a lo que le envuelve, es por el pensamiento por lo que sabe frente al no saber del resto del universo. $\mathrm{O}$, como explícitamente, dice en otra ocasión: "El pensamiento constituye la grandeza del hombre" $(759,346)$. Pero en Kant las cosas no son exactamente así. Lo que se contrapone al cielo estrellado sobre mí, no es el pensamiento en mí, sino la ley moral en mí. Ahora bien, sabemos que, para Kant, la condición de posibilidad de la ley moral no es otra que la libertad. Si el tema de la libertad humana es indecidible desde el punto de vista del uso teórico de la razón -tal como pone de relieve en el estudio de la tercera antinomia de la "Dialéctica de la razón", en la Crítica de la razón pura-, la razón, en su uso práctico, descubre una insoslayable condición de posibilidad del hecho moral, y no es otra que la libertad ${ }^{3}$. Esto es, si aceptamos la moralidad como un hecho irrebasable y del que no podemos prescindir, tenemos que aceptar también la condición que la hace posible, y sólo un ser libre es susceptible de deber moral. O, como el propio Kant indica desde la primera nota al "Prólogo" de la Crítica de la razón práctica, sabemos de la libertad por la moralidad, pero la razón de ser de la moralidad es la libertad: "la libertad es sin duda la ratio essendi de la ley moral, pero la ley moral es la ratio cognoscendi de la libertad" (Kant, 1972, 91). Así pues, lo que diferencia ante todo al hombre del resto de los animales y del universo en general, no es tanto el pensamiento cuanto la libertad, es decir, la capacidad de moralidad. Por eso, desde el comienzo de la Fundamentación de la metafísica de las costumbres, lo bueno sin restricción no va a recaer en los bienes materiales, ni en las cualidades del temperamento, ni en los rasgos de carácter, ni siquiera en los talentos del espíritu (entre los que

${ }^{3}$ Esta articulación está muy subrayada en el estudio de J. Muguerza, "Kant y el sueño de la razón” (Muguerza, 1991, especialmente pp. 19-20). 
Kant enumera el entendimiento y el Juicio), sino únicamente, y tanto en el mundo como en general fuera de él, en la "buena voluntad". Pues sin los principios de una buena voluntad otras cualidades pueden llegar a ser harto malas (Kant, 1996, 117-119) ${ }^{4}$. En fin, hasta tal punto Kant acentúa esa concepción de la dignidad humana que, en la Tercera sección de la Fundamentación, insistirá en que esa dignidad ni siquiera reside en nuestro modo de obrar, fenoménicamente comprobable, sino en nuestra capacidad de obrar moralmente, que es lo que hace que hasta el malvado haya de ser considerado, no como un simple medio, sino siempre como un fin en sí. Es posible, en todo caso, que libertad y razón se articulen en Kant más estrechamente de lo que aquí sugiero y, por tanto, que hubiera vías de aproximación con Pascal. Mas, sin entrar en similar problemática, no quería dejar de señalar una diferencia de acentos que, pese a las indicadas semejanzas, estimo importantes.

Tendremos ocasión de subrayar otras cercanías, sobre todo a propósito del carácter central que, tanto en Pascal como en Kant, tendrá la opción práctica, aspecto muy destacado en el estudio de L. Goldmann al que nos referimos. Más allá de ella, podría quizá atisbarse asimismo una línea de parentesco entre las insinuaciones pascalianas respecto al espanto producido por "los espacios infinitos" -superados, no obstante, por el pensamiento humano que los "envuelve"- y el concepto de lo sublime en Kant, cuya magnificencia nos anonada, estimulando, sin embargo, a la vez, a través de la contemplación de la grandeza sensible, la evocación de nuestra grandeza moral. Finalmente, y sin pretensión de exhaustividad, se podría incluso conectar -por la vía de la "belleza espantosa" a la que aludí al hablar del estremecimiento de Pascal ante el silencio eterno de los espacios infinitos- lo sublime kantiano y el concepto de "lo siniestro" en Freud, tal como fue elaborado por Eugenio Trías en su estudio sobre Lo bello y lo siniestro, que empieza, precisamente, recordando a Rainer María Rilke, según el cual "lo bello es el comienzo de lo terrible que todavía podemos soportar” (cit. en Trías, 1988, p. 17).

En todo caso, creo que Pascal puede ser considerado, con justicia, como el Newton de la filosofía kantiana de la religión (de manera similar a como Kant dijo que Rousseau era para él el Newton de la moral). Lo veremos asimismo a propósito del tema de la apuesta, tantas veces malentendida. Mas antes tenemos que considerar otros temas.

${ }^{4}$ Sobre la moralidad en Kant son excelentes los estudios de J. Rivera de Rosales (Rivera de Rosales, 2004 a y b). 


\subsection{El problema del conocimiento: la incertidumbre y la decisión}

La situación desproporcionada del hombre encuentra una de sus más altas expresiones en lo que al conocimiento humano se refiere. Como en Descartes, el problema básico del que parte Pascal es el de la certeza, el de saber a qué atenernos. Pero, mientras que Descartes hace de la duda un método, es decir, y como el propio término indica, un camino hacia la seguridad y la verdad, para Pascal la duda no es tanto una actitud metódica cuanto una condición existencial en la que nos encontramos y de la que no podríamos salir mediante ninguna vía que nos proporcionara el acceso a alguna proposición definitivamente poseída y asentada, sobre la cual pudiéramos más tarde reconstruir el mundo anteriormente puesto entre paréntesis. Será el tomar conciencia de este carácter de incertidumbre radical el que le lleve a señalar la necesidad de apostar, de elegir, de decidir, aunque dicha decisión tampoco será equivalente a una opción puramente arbitraria y muda de razones.

\subsubsection{La antítesis entre dogmatismo y escepticismo}

Los filósofos se han debatido siempre en el interior de la antítesis del dogmatismo y del escepticismo (o, como Pascal suele decir, del pirronismo, por Pirrón de Elis, el famoso escéptico de la Antigüedad). Los escépticos tienen razón al sostener que la razón es incapaz de ofrecer una demostración cabal de cualquier cosa, pero yerran al extraer de aquí la conclusión de que, entonces, es la suspensión del juicio la única posibilidad razonable. Y ese no poder acabar de demostrar, pero no por ello poder dejar de afirmar y de tomar partido, constituye nuestra condición: "Tenemos una incapacidad de probar, invencible para todo dogmatismo. Tenemos una idea de la verdad, invencible para todo pirronismo" $(406,395)$.

Nada desearíamos más que encontrar una base firme sobre la que se alzara una torre hasta el infinito, mas, cuando pensamos haberla encontrado, se desliza bajo nuestros pies y nos abandona:

He aquí nuestro verdadero estado; es lo que nos hace incapaces de saber ciertamente y de ignorar absolutamente. Bogamos en un vasto medio, siempre inciertos y flotantes, empujados de un extremo a otro. Si damos con un término a que pensamos vincularnos y en que pensamos afianzarnos, titubea y nos abandona; y si lo seguimos, se nos escapa de las manos, se desliza y nos huye con una fuga eterna. Nada se detiene por nosotros. Es el estado que nos es natural y, sin 
embargo, el más contrario a nuestra inclinación; ardemos en deseos de encontrar una sede firme y una última base constante para edificar sobre ella una torre que se alce hasta el infinito, pero todos nuestros cimientos se quiebran y la tierra se abre hasta los abismos. No busquemos, pues, punto de seguridad y de firmeza. Nuestra razón se ve siempre decepcionada por la inconstancia de las apariencias; nada puede fijar lo finito entre los dos infinitos que lo envuelven y le huyen" $(199,72)$.

Aunque la matemática ofrece un saber deductivo riguroso, no se puede hacer de ella el modelo para la filosofía, como pretendía Descartes. La crítica de Pascal no va a basarse, como lo hará Kant con posterioridad, en la imposibilidad de pasar del pensamiento a la existencia por mero análisis racional de un concepto (por cuanto la existencia, afirmará Kant, no es un predicado o cualidad que pudiéramos analíticamente descubrir, sino una "posición absoluta", esto es, algo que está absolutamente puesto frente al sujeto y que es preciso empíricamente descubrir), sino en dos órdenes de razones diferentes: la indemostrabilidad de los primeros principios y la relación entre el todo y las partes.

4.2.2. La indemostrabilidad de los primeros principios y los límites de la razón

Una proposición matemática, un teorema (el de Pitágoras, por ejemplo) no es algo de suyo evidente (no lo es el que, en un triángulo rectángulo, la suma de los cuadrados de los catetos sea igual al cuadrado de la hipotenusa), por lo que ha de ser demostrado en base a proposiciones más simples, amplias y claras. Pero, a su vez, si quisiéramos probar éstas tendríamos que remontarnos a otras, y en ese camino de regresión, o de ascenso, acabaríamos por llegar necesariamente a términos tan primitivos que ya no se pueden definir y a principios tan claros que ya no encontramos otros más claros que puedan probarlos. Esos primeros principios se dice, efectivamente, que no se demuestran: no son teoremas, sino axiomas o postulados, que se "ponen" sin demostración porque se consideran de suyo evidentes. Su aceptación no reposa, pues, en demostración alguna sino en su presunta claridad. Sin entrar en la cuestión de que esa evidencia puede ser puesta en entredicho (como en el siglo XIX harán las geometrías no euclidianas al cuestionar el postulado $\mathrm{V}$ de Euclides, según el cual por un punto exterior a una recta sólo puede trazarse una paralela a ella), Pascal quiere hacer notar que incluso la certeza matemática se basa en otro orden distinto de la razón, y al que denomina orden del "corazón". "Es de esta manera como conocemos los primeros principios", lo cual no descalifica el conocimiento, pero deslegitima la ilusión de que todo en él es absolutamente racional. Esta incapacidad no ha de 
servir, pues, sino para humillar a la razón, que quisiera juzgarlo todo, pero no para combatir nuestra certeza:

Conocemos la verdad no solamente por la razón, sino también por el corazón. Es de este último modo como conocemos los primeros principios, y en vano el razonamiento que no tiene parte alguna en ello, intenta combatirlos. Los pirronianos, que no tienen por objeto más que eso, trabajan inútilmente. Sabemos que no sońamos en absoluto. Sea cual fuere la incapacidad en que nos encontremos para probarlo por la razón, dicha incapacidad no concluye otra cosa que la debilidad de nuestra razón, pero no la incertidumbre de todos nuestros conocimientos, como ellos pretenden. Pues los conocimientos de los primeros principios: espacio, tiempo, movimiento, números, son tan firmes como los que nos dan nuestros razonamientos, y sobre esos conocimientos del corazón y del instinto es preciso que se apoye la razón y que fundamente todo su discurso [...]. Esta incapacidad no debe servir, pues, más que para humillar a la razón -que quisiera juzgarlo todo-, pero no para combatir nuestra certeza. ¡Cómo si sólo la razón fuera capaz de instruirnos! (110, 282).

Esta limitación de la razón no implica, por tanto, para Pascal, ninguna suerte de abandono en el irracionalismo, sino la destrucción del espejismo racionalista. "El último paso de la razón consiste en conocer que hay una infinidad de cosas que la sobrepasan. Es débil si no alcanza a conocer esto" $(188,267)$. Y ésa es, al cabo, la actitud más racional. "Dos excesos: excluir la razón, no admitir más que la razón” $(183,253)$.

Hay que saber dudar donde es necesario, aseverar donde es necesario, sometiéndose donde es necesario. Quien no lo hace no escucha la fuerza de la razón. Los hay que pecan contra estos principios, o bien aseverándolo todo como demsotrativo, por no entender de demostraciones; o bien dudando de todo, por no saber donde hay que someterse; o bien sometiéndose a todo, por no saber dónde hay que juzgar $(170,268)$.

\subsubsection{El todo y las partes: concepción lineal y concepción dialéctica}

Mas, aun cuando hubiésemos encontrado una proposición firmemente establecida por la razón, no podríamos pensar por ello que la conocíamos en profundidad y sin necesidad de revisarla en función de ulteriores conocimientos, debido 
a que la relación entre el todo y las partes no es una relación lineal, sino, por utilizar la terminología de L. Goldmann, que es quien ha puesto estos aspectos de relieve, dialéctica. En efecto, aun sin utilizar esas categorías, Pascal critica la posibilidad de refugiarse en un conocimiento parcial, pero sólido, de la realidad, como pretendía hacer Descartes.

Para Goldmann, la relación entre el todo y las partes se ha concebido históricamente de dos maneras diferentes: para la concepción lineal, aunque no podamos conocer el todo, sí podemos establecer con certeza algunas de sus partes, a partir de las cuales avanzaremos en el conocimiento en un progreso lineal e indefinido. Para la concepción dialéctica, en cambio, aunque el conjunto sólo puede ser conocido a través del progreso en el conocimiento de las verdades parciales, éstas sólo adquieren su verdadera significación por relación al todo (o a totalidades más o menos relativas):

Así, frente al atomismo racionalista y empirista, que mantienen la ilusión de poder partir de una serie de conocimientos adquiridos, dados de una vez -bien sea de las ideas innatas o de la sensación o percepción-, a partir de los cuales el pensamiento sigue un discurso lineal sin tener que volver normal y necesariamente sobre los problemas ya resueltos, para el pensamiento dialéctico, hacia el cual Pascal representa el gran giro, no existen puntos de partida fijos ni problemas resueltos de una vez por todas.

En efecto, los más diversos aspectos de la realidad se hallan relacionados entre sí, de manera que el pretendido conocimiento aislado y particularista de ellos ha de ser criticado, teniendo en cuenta las relaciones en que se encuentran, y sin las cuales aquél, no sólo es parcial, sino también equívoco. Conocer es, en buena medida, relacionar, saber los nexos que algo guarda con el resto del universo. Esas relaciones que las cosas y las personas tienen con lo demás es lo que nos otorga su sentido y su significación y, sin éstos, cualquier conocimiento aislado, por exhaustivo que sea, no resulta sino limitado y superficial. Por lo que conocer algo en profundidad requiere verlo a la luz del todo (o de totalidades cada vez más amplias) que nos ofrecen su sentido. De ahí que si para llegar al todo es preciso pasar por las partes, éstas han de ser continuamente reexaminadas desde aquél, modificándose entonces el primer conocimiento que de ellas tuviéramos, que no puede ser considerado nunca definitivo. Pascal parece haber sido enormemente lúcido a este respecto:

\footnotetext{
5 L. Goldmann, El hombre y lo absoluto, cit., p. 15.
} 
Manteniéndose todas [las cosas] por un nexo natural e insensible que liga las más alejadas y las más diferentes, tengo por imposible conocer las partes sin conocer el todo, así como conocer el todo sin conocer particularmente más partes $(199,72)$.

Y por eso ironiza sobre aquellos filósofos que, comprendiendo que han de renunciar a alcanzar lo infinito, pretenden sin embargo poder llegar a conocer los primeros principios, sin advertir que se trata de un problema similar, pues en la medida en que no conozcamos la circunferencia, tampoco podremos decir de un punto si es o no centro:

Pero la infinidad en lo pequeño es mucho menos visible. Los filósofos han pretendido, sin embargo, llegar a ella, y ahí han fracaso todos. Es lo que ha dado lugar a títulos tan corrientes como De los principios de las cosas, De los principios de la filosofía, y otros semejantes de efecto tan fastuoso, aunque aparentemente menos que este otro que hace saltar los ojos: De omni scibili ["De todo lo que se puede saber". Pascal alude sin duda al tratado del mismo título de Pico della Mirandola, al que un bromista, quizá Voltaire, añadió: et quibusdam aliis, "y algunas cosas más”. Con todo, quizá el título más ambicioso posible, lo propondría, siglos después, Sartre: El ser y la nada]. Se cree, naturalmente, ser mucho más capaz de llegar al centro de las cosas que de abarcar su circunferencia [...]. Y, sin embargo, no hace falta menor capacidad para llegar hasta la nada que para llegar hasta el todo; y es menester tenerla infinita tanto para lo uno como para lo otro, y me parece que quien hubiera comprendido los últimos principios de las cosas podría llegar también a conocer hasta el infinito $(199,72)$.

\subsection{4. “Razón” y “corazón”. Espíritu de geometría y espíritu de finura}

Pero, por limitado y parcial que su conocimiento sea, el hombre ha de servirse, además de la razón, del "corazón”. El término empleado por Pascal es ambiguo y, entre otras, ha dado lugar a una interpretación romántica, en la que se pretendía ver en él una alusión sentimental. Difícilmente podría ser así, cuando Pascal, como ya hemos visto, dejó dicho que "es por el corazón como conocemos los primeros principios" $(110,282)$, y no parece que éstos sean asequibles al sentimiento. Es cierto, desde luego, que el estatuto epistemológico del "corazón" no está demasiado claro en Pascal. Por otros fragmentos sabemos también que "Dios es sensible al corazón, no a la razón" $(424,278)$, e incluso, como ha llegado a ser célebre, que "el corazón tiene razones que la razón no conoce" (423, 277). Mas, 
con independencia de la falta de claridad al respecto, parece que Pascal quiere apuntar con ese término a una estructura compleja de certezas no demostradas racionalmente, pero no por ello menos valiosas ni estrictamente irracionales, sino que más bien desbordan la razón, sin por ello conculcarla, y que, como veremos, exigen una "decisión práctica".

Sea de ello lo que fuere, lo cierto es que la estructura razón-corazón, se encuentra en el origen de una variedad casi infinita de formas de espíritu (entendiendo por tal una disposición permanente, una especie de tipo intelectual), que Pascal intenta clasificar, siendo la más célebre la distinción entre espíritu de geometría (esprit de géométrie) y espíritu de finura (esprit de finesse) (Cfr., p. ej., 512, 1). Los primeros tienen el don de razonar; los segundos, el de descubrir, bajo la masa y el detalle de los razonamientos y de la experiencia, los principios a los que se conforman. El ideal sería que los geómetras tuvieran espíritu de finura y los capaces de finura espíritu geométrico, pero la observación psicológica muestra que esto no suele suceder.

\subsubsection{Una decisión razonable}

De este modo, para Pascal, el problema de la certeza no se resuelve encontrando una proposición últimamente demostrada y no necesitada de revisión (ambas cosas, como hemos visto, resultan inviables). Pero ello no implica forzosamente un abandono en el escepticismo. Más bien parece que la propia razón sabe que es superada por un orden de realidad al que habrá en ocasiones de someterse, orden no asequible de modo estrictamente racional, pero tampoco irracional, pues aunque no esté últimamente demostrado no por ello contraviene a la misma razón, sino que incluso parece exigido por ella. Ese orden del corazón se referiría tanto a la captación intuitiva de los primeros principios, como a la aprehensión amorosa de Dios. Lucien Goldmann ha aproximado de nuevo aquí Pascal a Kant, al interpretar que lo que Pascal plantea con tal término es la exigencia de una decisión práctica equivalente a lo que Kant denominará una "fe racional” y que quizá fuera más adecuado calificar como "opción razonable". En efecto, para él, el corazón supone la aparición, al lado de las dos facultades tradicionales de la sensibilidad y el entendimiento, de una tercera facultad definida por el hecho de exigir (en Pascal y en Kant) o de empujar al hombre a realizar (en Hegel y Marx) la síntesis de los contrarios en general y de las otras dos facultades en particular; una facultad a la que Kant, Hegel y Marx denominarán más tarde razón (Vernunft) en oposición al entendimiento (Verstand) (cuyos análisis particularistas habría de criticar desde totalidades cada vez más amplias), que es a lo 
que Descartes denominaba razón. Es mérito de Pascal haber tematizado, quizá un tanto toscamente aún, pero no por ello con menos energía, la necesidad de esa "apuesta razonable" en la que el hombre se encuentra.

Con Pascal penetran en la filosofía práctica tres elementos fuera de los cuales no se puede comprender la condición humana en su realidad concreta: el riesgo, el peligro de fracaso y la esperanza de éxito [...]. No es de los menores títulos de gloria de Pascal el haberlos hecho entrar explícitamente en la historia de la filosofía (Goldmann, 1968, 395-398).

La necesidad de la apuesta se le manifesta a Pascal al advertir que si, en vista de nuestro estado de incertidumbre -en el que parece que no podemos saberlo todo, pero también que no ignoramos del todo-, adoptamos una actitud escéptica, esa actitud es también ya una elección, además de resultar inviable en sus últimas consecuencias:

¿Qué hará pues el hombre en este estado? ¿Dudará de todo? ¿Dudará de si vela, de si se le pellizca, de si se le quema?, ¿¿dudará de si duda?, ¿dudará de si existe?

No se puede llegar hasta ahí, y doy por sentado que no ha habido jamás un pirroniano perfecto. La naturaleza sostiene a la razón impotente, y le impide disparatar hasta ese punto.

¿Dirá, pues, por el contrario, que posee ciertamente la verdad, él que a poco que se le acose, no puede mostrar ningún título de ella y se ve forzado a abandonar la presa? $(131,434)$.

Lo que parece imponerse entonces es una opción, que no necesariamente se decanta por el escepticismo, ya que, puestos a dudar, también podríamos, como proponía Juan de Mairena, el personaje apócrifo de A. Machado, dudar de la propia duda -que es algo diferente al "dudar de si duda" al que se refiere Pascaly decidirnos por la opción que nos parezca más razonable. Pero de lo que no estamos eximidos es de la necesidad de elegir en condiciones de incertidumbre y la propia actitud escéptica es una de esas opciones. La apuesta, entonces, no es una decisión irracional, sino, al contrario la actitud razonable. Pascal, que insistirá en el tema a propósito de la cuestión de la existencia de Dios, no ha dejado de mostrar que, con todas las diferencias pertinentes, ése es también el caso en la mayor parte de las situaciones existenciales en las que el hombre se encuentra 
inmerso. Ahora bien, trabajar por lo incierto y apostar, eso es precisamente lo razonable: Si no se debiera hacer nada sino por lo cierto [...] no podría hacerse nada por nada, porque nada es cierto. Ahora bien, trabajar por el mañana, y por lo incierto, es obrar razonablemente $(577,234)$.

En estas condiciones es en las que Pascal va a abordar la cuestión religiosa, a la que dedicaremos nuestro último apartado.

\section{En busca de Dios: "No me buscarías si no me hubieses encontrado..."}

\subsection{El discurso frente a la indiferencia}

En diversas ocasiones se ha hecho notar que el principal interlocutor al que se dirigen los Pensamientos, no es tanto el ateo, como el indiferente. Y es esa indiferencia la que se quiere ante todo socavar. En efecto, una de las salidas de la condición de incertidumbre en la que el hombre se encuentra es evadirse mediante la diversión y el olvido de sí. Quizá Pascal sea en esto excesivamente rigorista, pues la vida humana es también descanso de la preocupación de existir y di-versión. Bien es verdad, que más que descansar y di-vertirse, muchas veces, lo que el hombre parece buscar es atolondrarse, aturdirse. Lo que menos podría soportar es permanecer en reposo en una habitación, lo que le recordaría su condición mortal, de la que huye. No son los objetos que dice buscar lo que le interesa, sino que es la búsqueda lo que le entretiene. Por eso prefiere la caza a la presa, le gustan los bailes (hay que pensar dónde se ponen los pies), el ruido y el alboroto: "Creen buscar sinceramente el reposo, y no buscan, en verdad, más que la agitación” $(136,139)$.

Nada es tan insoportable para el hombre como estar en pleno reposo, sin pasiones, sin quehaceres, sin divertimiento, sin aplicación. Siente entonces su nada, su abandono, su insuficiencia, su dependencia, su impotencia, su vacío. Irresistiblemente surgirán del fondo de su alma el tedio, la maldad, la tristeza, la pesadumbre, el despecho, la desesperación $(622,131)$.

El problema, entonces, no es tanto que el hombre busque divertirse cuanto que, con lo que llama diversión, busca la verdadera felicidad donde no la puede encontrar y trata a toda costa de olvidar su condición mortal. Por eso, una vez acabada la diversión, viene de nuevo el aburrimiento y el hastío. 
La única cosa que nos consuela de nuestras miserias es el divertimiento $y$, sin embargo, es la más grande de nuestras miserias. Porque es lo que nos impide principalmente pensar en nosotros y lo que nos hace perdernos insensiblemente $(414,171)$.

Su falta no consiste en que busquen el tumulto, si no lo buscaran más que como un divertimiento; lo malo es que lo buscan como si la posesión de los bienes buscados fuera a hacerles verdaderamente felices $(136,139)$.

Como subraya Aranguren, el hombre "huye de lo que está justificado llamar, en Pascal, la obsesión existencial que, haciéndole caer en la cuenta de que no hay nada en la naturaleza que pueda satisfacerle, le haría volverse a Dios, ya que Él sólo es su verdadera felicidad" (Aranguren, 1997, 605).

\subsection{El discurso frente a la vanidad. Rigorismo de Pascal}

Pero el acceso a Dios es difícil, no sólo a causa de su no evidencia, del Dios oculto, sino también por la vanidad del hombre, al que le gustaría ocupar, él mismo, el puesto de Dios: Unusquisque sibi deum fingit, "cada uno se forja un dios de sí mismo" $(755,258)$. De ahí que, no sólo el necesario reconocimiento, sino el orgullo y el deseo de ser estimados sin medida lleven a perder el sentido de la justicia, e incluso la vida misma, sacrificada al yo imaginario, al qué dirán: "Trabajamos incesantemente en embellecer y conservar nuestro ser imaginario, descuidamos el verdadero" $(806,147)^{6}$. O también: "Vanidad, juego, cazas, visitas, comedias, falsa perpetuidad del nombre" $(628,153)$.

La imaginación, "maestra de error y falsedad" $(44,82)$, "agiganta los pequeños objetos hasta llenar con ellos nuestra alma, por una estimación fantástica; y por una insolencia temeraria empequeñece los grandes hasta su medida, como al hablar de Dios" $(551,84)$.

El amor propio nos hace olvidar nuestra verdadera condición. Así, no podemos soportar la verdad, sino cuando se nos sirve azucarada y, aun así, nos disgusta. Y sabiéndolo, todos disimulan:

${ }^{6}$ Este texto podría haber hecho las delicias -si es que no las hizo, es decir, si es que no se inspiró en él, dado su interés por los moralistas franceses- de J. Lacan y su distinción entre el moi y el je. 
Por eso sucede que, si uno tiene algún interés en ser amado por nosotros, se aparta de prestarnos un servicio que sabe que nos es desagradable; nos trata como queremos ser tratados: odiamos la verdad, nos la oculta; queremos ser adulados, nos adula; nos gusta ser engañados, nos engaña.

Esto es lo que hace que cada grado de buena fortuna que nos eleva en el mundo nos aleja más de la verdad, porque se teme más herir a aquellos cuyo aprecio es más útil y cuya aversión es más peligrosa. Un príncipe será el hazmerreír de toda Europa, y él será el único que no lo sabrá. No me sorprendo por ello: decir la verdad es útil para aquel a quien se le dice, pero desventajoso para los que la dicen, porque se hacen odiar [...]. Así, la vida humana no es sino una ilusión perpetua; no se hace más que engañarse y adularse recíprocamente $(978,100)$.

Es ese olvido de sí y de Dios, en la preocupación por ser yo, el que le lleva a Pascal a exclamar: "El yo es odioso" $(597,455)$, una "protuberancia odiosa de palabras vanas", apostilla Albiac, comentándole (Albiac, 1985) 7 Parece como si el yo, para Pascal, fuera un lenguaje de declaración de guerra: el lenguaje del hombre separado de Dios, que se toma por un dios. Y es a ese hombre al que los Pensamientos quieren dirigirse, para disponerle a afrontar su humana condición, quizá expuesta, en todo caso, de un modo excesivamente pesimista. Sin negar la denuncia de Pascal, sin negar los tonos sombríos con que describe al hombre, la vanidad infinita que tantas veces preside las relaciones humanas, no todo en ellas tiene esa coloración, ese tenor. Hay también momentos de entrega, de generosidad, e incluso de heroísmo cotidiano (entreverado, si se quiere, con las actitudes por él fustigadas, pero no por ello menos cierto) que habrían de ser asimismo destacados. Pues, pese a todo, hasta un autor nada "ingenuo" como Camus, decía al final de La peste que "hay más cosas en el hombre dignas de admiración que de desprecio".

¿No habría de pensar otro tanto Pascal, al partir de una concepción cristiana del hombre, en cuanto "imagen y semejanza de Dios", por desastrosas que sean las consecuencias que quiso tematizar el tema de "la caída"? ¿No olvida demasiado fácilmente los aspectos positivos de la existencia humana el Pascal que escribe: "Condición del hombre. Inconstancia, tedio, inquietud" (24, 127). "El hombre sabe que es miserable. Es, pues, miserable por lo que es; pero es grande porque lo sabe" $(122,416)$ ? Hans Küng va en esta dirección, en las preguntas finales que

\footnotetext{
7 Cf. también del mismo autor: Albiac, 1981 y 2013.
} 
dirige, no sólo a Pascal, sino a toda la tradición agustiniano-reformista: “¿Hay que odiar el propio yo para amar a Dios de corazón? El camino cristiano hacia Dios, ¿̨no pasa más bien por la donación al tú que por la aniquilación del yo: por el amor al prójimo (jsegún la medida del amor a sí mismo!) como plenitud del amor a Dios?” (Küng, 1979, 127). Y en cuanto al esfuerzo ascético, a costa de lo humano del propio yo, no hay duda de que cuenta con muchísimos modelos en las religiones no cristianas, pero casi nada tiene que ver con la vida y la doctrina de Jesús. La condena de la riqueza en los Evangelios se hace en función de la pobreza para muchos que genera la opulencia de unos pocos y porque un apego excesivo al mundo nubla, si es que no borra, la dimensión de trascendencia. Pero el mundo mismo no es negado, ni los momentos de cordialidad, alegría y distensión, de complicidad amorosa entre los hombres. En fin, y sin quitarle grandeza, ¿no olvida demasiado fácilmente la piedad jansenista, con su unilateral individualismo interiorizado, la dimensión política del hombre? Varios pensamientos sobre las leyes nos recuerdan que Pascal no fue tan apolítico como a primera vista podría parecer, pero, sin duda, esas preocupaciones no son el eje central de su obra.

\subsection{Imposibilidad y futilidad de las “pruebas" de la existencia de Dios}

Ese eje, como decíamos, es sacudir la indiferencia del hombre (indiferencia recubierta de vanidad), a fin de que no sea insensible a la dimensión de trascendencia a la que está abocado. Pascal, personalmente, está convencido de la existencia de Dios: "No me buscarías si no me hubieses encontrado" $(918,553)$. Mas, en cuanto filósofo, y hubiera Dios o no, "el hombre sobrepasa infinitamente al hombre" y desemboca en esas cuestiones, si es que su temor y su angustia no le lleva a reprimirlas. Como también Kant advertirá en la "Introducción" a la Crítica de la razón pura, con independencia de que el hombre sea capaz o no de contestarlas, la razón humana avanza incontenible hacia esas cuestiones, "sin que sea sólo la vanidad de saber mucho quien la mueve a hacerlo" (Kant, 1985, 55). A esas preguntas que quizá nos incomoden, pero que son las únicas que hacen justicia, a fin de cuentas, a nuestra condición es a las que quieren llevar los Pensamientos de Pascal:

¿Qué quimera es, pues, el hombre? ¿Qué novedad, qué monstruo, qué caos, qué sujeto de contradicción, qué prodigio! Juez de todas las cosas, imbécil gusano, depositario de la verdad, cloaca de incertidumbre y error, gloria y excrecencia del universo. 
¿Quién desenredará este lío? La naturaleza confunde a los pirrónicos, y la razón confunde a los dogmáticos. ¿Qué será, pues, de vosotros hombres, que buscáis cuál es vuestra verdadera condición por vuestra razón natural? No podéis huir de una de estas sectas, ni subsistir en ninguna.

Reconoced, pues, soberbios, qué paradoja sois para vosotros mismos. Humillaos razón impotente; callad, naturaleza imbécil; sabed que el hombre supera infinitamente al hombre y escuhad de vuestro maestro vuestra verdadera condición que ignoráis.

Escuchad a Dios $(131,434)$.

No obstante, la existencia y la naturaleza de Dios son inaccesibles al hombre:

Conocemos la existencia y la naturaleza de lo finito, porque también nosotros somos finitos y extensos. Conocemos la existencia de lo infinito y somos ignorantes de su naturaleza, porque, aunque como nosotros tiene extensión, a diferencia de nosotros no tiene límites. Pero no conocemos ni la existencia ni la naturaleza de Dios, porque Dios no tiene extensión ni límites. Ahora bien, por la fe conocemos su existencia, y por la gloria conoceremos su naturaleza [...]. Si hay un Dios, es infinitamente incomprensible; porque al no poseer partes ni límites, no tiene relación alguna con nosotros. Somos, pues, incapaces de saber lo que es, ni si es $(418,233)$.

Aunque, en realidad, Dios no es solamente un "Dios oculto" para los hombres, sino más bien, como pone de manifiesto en la carta a Mme. de Roannez, un Dios, a la vez, presente y ausente:

Si Dios se descubriese continuamente a los hombres no tendría ningún mérito creer en él; si no se descubriese nunca habría poca fe. Pero se oculta generalmente y se descubre raramente a aquellos a quienes quiere atraer a su servicio. Ese extraño escondite, al que Dios se ha retirado, es una gran lección para llevarnos a la soledad, lejos de los ojos de los hombres (Cit. en Villar, 1987, 178).

Las pruebas tradicionales de la existencia de Dios son, no sólo dudosas, sino ineficaces. Dudosas, porque, aunque no todo lo expuesto en ellas sea baladí, su razonamiento no acaba de ser convincente. Ineficaces, porque a lo más que alcanzan es a un concepto vago y abstracto de Dios, que poco tiene que ver con 
el Dios de las religiones y, en concreto, con el Dios bíblico, el "Dios de Abraham, de Isaac y de Jacob”, y, sobre todo, el "Dios Amor” de Jesús.

Las pruebas metafísicas de Dios están tan alejadas del razonamiento humano y son tan complicadas que tienen poco efecto. E incluso cuando sirven para ciertas personas, sirven solamente en el momento en que aquellas ven la demostración. Una hora más tarde ya temen haber podido ser engañadas $(190,543)$.

A Pascal no le interesa un Dios demostrado, algo por lo demás imposible y que dispensaría de la actitud de confianza, que es la que para el acceso a Dios se requiere. Pero tampoco una fe puramente irracional, por la que se pudiera creer en cualquier arbitrariedad. Por eso, la fe no puede ni depender por completo de la razón (que la anularía) ni prescindir por completo de ella (que la tornaría caprichosa):

La razón no se sometería jamás si no juzgase que hay ocasiones en las que se debe someter. Es, pues, justo que se someta cuando juzgue que debe someterse $(174,270)$.

Si se somete todo a la razón, nuestra religión no tendrá nada de misterioso ni de sobrenatural. Si se choca contra los principios de la razón, nuestra religión será absurda y ridícula $(173,273)$.

\subsection{Le pari, la apuesta}

De ahí que Pascal anticipe de nuevo a Kant al insistir en este punto en la necesidad de una apuesta práctica, que cada cual hará por la opción que le parezca más razonable. En esa opción, Kant destaca la importancia de la vida moral (un mandato de la razón) que nos permite esperar razonablemente en la existencia de Dios y en la inmortalidad. Es muy posible que, junto a ese aspecto central, haya muchos otros (experiencias biográficas, mediaciones sociales, vivencias estéticas, etc.) que acaben decidiendo en un sentido o en otro. Pero, lo que a Pascal le interesa ante todo resaltar es la importancia de la elección, a la que dedica uno de sus más amplios fragmentos, el famoso de le pari, la apuesta: "Es preciso apostar. No es voluntario, estáis embarcados" $(418,233)$.

El desarrollo concreto del argumento ha confundido en alguna que otra ocasión. Para Pascal, dada la incertidumbre en la que nos encontramos, donde no 
es seguro (desde un punto de vista estrictamente racional) que exista Dios, pero tampoco ni mucho menos que no exista, la apuesta siempre debe ser a favor de su existencia, pues si lo hacemos así y no existe no perdemos nada, pero si existe lo ganamos todo: "Apostad, pues, a que Él existe sin vacilar".

Pero, cuando coloca al hombre ante la apuesta, no parece que Pascal pretenda ofrecer un mero cálculo utilitarista (que hubiera despreciado), ni un nuevo intento de demostración (que habría desechado), ni siquiera un puro echar a suerte (que trivializaría la cuestión) o un cálculo de probabilidades (aunque ciertos desarrollos puedan dar esa impresión), sino más bien mostrar la racionalidad misma de la opción en el riesgo. La función, pues, del argumento en torno a la apuesta no es substituir una ignoracia por un conocimiento, sino provocar una situación en la que la ignorancia no llegue a ser indiferencia.

Finalmente, se presenta el caso del incrédulo que quiere creer, que incluso estima debería hacerlo y, sin embargo, no puede, por la fuerza de sus costumbres y de sus pasiones. Y aquí es donde Pascal le aconseja que, entonces, debe hacerlo todo como si creyera y que esa actitud le hará creer y "le embrutecerá":

Daos cuenta, por lo menos, de vuestra incapacidad de creer, puesto que la razón os conduce a ello y que, sin embargo, no podéis creer. Trabajad, pues, no en convenceros aumentando las pruebas de Dios, sino disminuyendo vuestras pasiones. Queréis llegar a la fe y no conocéis el camino; queréis curaros de la infelicidad y solicitáis el remedio: aprended de quienes han estado atados como vosotros y que ahora ponen en juego todo lo que tienen; son gentes que conocen este camino que quisierais seguir, y que están curados de un mal del que queréis curaros. Seguid la manera como han comenzado, haciéndolo todo como si creyeran, tomando agua bendita, haciendo decir misas, etc. Naturalmente, hasta esto os hará creer y os embrutecerá $(418,233)$.

Pese a las críticas que este pasaje ha suscitado, es obvio que Pascal no quiere olvidar la razón, pues de lo que se trata es de seguirla, disminuyendo las pasiones. Mientras para Descartes esta disminución despejaba el camino recto de la razón, para Pascal la razón puede comprender, a pesar de las pasiones, el carácter argumentativo de una demostración, y entonces ve el peligro de esas mismas pasiones -que no bloquean por completo el ejercicio de la razón, pero disuaden de seguir el camino por ella marcado- y exige que se aminoren, "embruteciéndose". De este modo, aunque la razón está mediada biográfica y socialmente, goza de un 
margen de autonomía por el que puede aceptar argumentos que vayan en contra de los intereses particularistas e instar a nuevas actitudes, si bien la adopción de esas nuevas actitudes no depende ya sólo de ella misma.

¿La apuesta por una ilusión? Como se sabe, el tema de la religión como ilusión, en el sentido de algo ilusorio, sería destacado por la crítica de la religión del XIX, asociada fundamentalmente a ese gran cuarteto formado por Feuerbach, Marx, Nietzsche y Freud. No podemos entrar en el detalle de la misma ni en los perfiles de una posible crítica de tal crítica $^{8}$. Pero lo que querría destacar ahora es que, aunque ésa es la atribución usual, quien introdujo el tema de la religión como ilusión en filosofía no fue ninguno de ellos, sino Kant, quien se refiere a Dios en la Dialéctica trascendental de la Crítica de la razón pura como un Schein trascendental. Schein, brillo, apariencia, ilusión en efecto, y ello no sólo por ser una ilusión necesaria (en el sentido en que la razón, búsqueda de lo Incondicionado, se ve abocada - por decirlo con Adorno que parafrasea ahí a Kant-, si no se decapita, a la Trascendencia: no como saber, y por lo tanto no como aseveración, ni siquiera como creencia, pero sí al menos como problema), sino sobre todo por ser necesariamente ilusión, por jugarse forzosamente en ese campo (lo que no implica que haya de ser necesariamente ilusoria). Tal estatuto hace estar de más ciertas exigencias que, en ocasiones, olvidando esa lección kantiana, se le hacen al creyente, como cuando se le pide que sea él quien cargue con el peso de la prueba. Y no es que yo quiera ponerle las cosas fáciles al creyente. Me temo que ahí sería bastante exigente, si es que no rigorista. De lo que se trata no es de poner las cosas fáciles ni difíciles, sino de ponerlas en su lugar. Y creo que la demanda de prueba en ese ámbito rebota más sobre el que la ejerce -y sus supuestos- que sobre el que no la cumple, pues resulta incumplible. Y es que, como ya observaba Pascal, lo peor no es que muchos no sepan muchas cosas, lo peor es que no saben ignorar, y así lo confunden todo, exigiendo pruebas donde sólo cabe conjeturar y conformándose con conjeturas donde deberían llegar a demostrar. Que es quizá por lo que, al final del "Canon", cuando pretende diferenciar entre la persuasión y la convicción, la opinión, el saber y la creencia, Kant observaba que, en estas cuestiones, si el opinar es poco, el saber resulta excesivo.

La opción por Dios a la que nos insta Pascal no es corroborada por la razón, pero tampoco contradicha por ella, sino que se perfila como una opción razonable, que cada cual podrá efectuar en función de las diversas mediaciones que le

8 Cf. C. Gómez, "Ética y religión”, en C. Gómez y J. Muguerza, eds., 2007, cap. 7. Respecto a Freud, C. Gómez 1998 y 2002. 
constituyen y de la lectura de fondo que haga de la realidad, sin excluir la legitimidad racional de otras opciones. Es posible que, en última instancia, creyentes $\mathrm{y}$ ateos ( $\mathrm{y}$ los diversos tipos y pelajes que dentro de cada uno de esos grupos se dan), para justificar sus elecciones, hayan de acudir a elementos narrativos, desde los que traten de hacer ver por qué a cada uno de ellos les resulta más plausible y mejor la suya. Mas, en la medida en que quisieran sortear la actitud dogmática (es decir, aquella que da por cancelado lo que, en realidad, resulta controvertible), habrían de seguir admitiendo, pese a su convicción personal de fondo, la posibilidad racional de otras, por cuanto una convicción es más que una simple persuasión, por ańadir a los elementos subjetivos, ciertos elementos objetivos, mas no tanto como para desembocar en un saber, sino tan sólo para sustentar una creencia. El dogmatismo sobrevendría cuando, queriendo traspasar esas fronteras y asegurarse, se pretendiera dar por conclusas cuestiones que, presumiblemente, sólo pueden quedar abiertas.

\section{Una obra en la frontera}

En cualquier caso, fuera cual fuese la opción de cada cual, y a pesar de los tintes, quizá en exceso sombríos, con que describe al hombre, Pascal ha querido taponar su frecuente tendencia a evadirse y a aturdirse, por miedo a su fragilidad y su vacío, enfrentándolo con esa nuestra humana condición, en buena medida trágica, pero tal vez también, y a pesar de todos los pesares, hermosa. Una condición en la que el hombre sobrepasa infinitamente al hombre, como a él le gustaba decir, y vive, desde su existencia finita y temporal, en el filo de lo incondicionado y eterno, que a la razón se le aparece como un brillo que vislumbra, pero no alcanza.

Según Kolalowski indicaba, comentando a Pascal a este respecto:

Frente a las cosas eternas uno sólo es el cometido de la razón: tomar distancias respecto de sí misma y fijar los límites de sus posibilidades. Fuera de estos límites permanece lo que sólo al amor es accesible -"un ámbito infinitamente superior"-, aunque tampoco el amor conseguirá sacarnos de lo finito y transformarnos en dioses. La grandeza del hombre es determinada por la razón, pero la razón, para conservar su propia grandeza, debe reconocer y expresar ante todo su propia limitación [...]. Siempre que nuestro pensamiento va más allá de sí mismo, se esfuerza por afirmarse como pensamiento sobre lo infinito; la antinomia se convierte en el pan nuestro de 
cada día [...]. Cada frontera particular es franqueable, pero la existencia de la frontera misma no lo es (Kolakowski, 1971, 66-67).

No cabe duda de que Pascal ha sido uno de los más grandes testimonios de esos hombres que, en el mundo moderno, han sabido vivir en el incómodo territorio de la frontera entre racionalidad y creencia, entre ciencia y moral, entre vida temporal, condicionada y finita, y aspiración a lo eterno, incondicionado e infinito, y ha instado a que cada cual se atreva, desde sus propias circunstancias, a esa experiencia. Para los que este tipo de vivencias y de reflexiones sean desagradables o estén de más (como lo estuvieron, por ejemplo, para un cierto tipo de positivismo y neopositivismo, para los que no había más que problemas, pero nunca misterios) su obra resultará estéril, cuando no repugnante. En cambio, para todos aquellos que, sin rechazar las aportaciones de la ciencia -como el propio Pascal no las rechazó-, estimen, no obstante, y por decirlo con Wittgenstein, que "aun cuando todas las posibles cuestiones científicas hayan recibido respuesta, nuestros problemas vitales todavía no se han rozado en lo más mínimo" (Wittgenstein, 1973, prop. 6.52, p. 181), encontrarán en Pascal el testimonio y la obra de un hombre que, como pocos, ha sabido hacerse cargo de los desafíos de la fronteriza condición humana en los complejos derroteros de la Modernidad. 


\section{REFERENCIAS CITADAS}

\section{OBRAS DE PASCAL}

En francés

Pascal, B. (1963). Oeuvres complètes, préface d'Henri Gouhier, présentation et notes de Louis Lafuma, París, Seuil.

Pascal, B. (1964-1992). Oeuvres complètes, texte établi, presenté et annoté par Jean Mesnard, París, Desclée de Brouwer. (4 de 7 vols.).

Traducciones

Pascal, B. (1962). Pensamientos, trad. de X. Zubiri, Madrid, Espasa-Calpe, 6a ed.

Pascal, B. (1976). Pensamientos, trad. de E. d'Ors, Barcelona Iberia, $3^{\mathrm{a}}$ ed.

Pascal, B. (1981a). Obras, prólogo de J. L. L. Aranguren, trad. y notas de Carlos R. Dampierre, Madrid, Alfaguara.

Pascal, B. (1981b). Pensamientos, trad., introducción y notas de J. Llansó, Madrid, Alianza.

Pascal, B. (2012). Obras, estudio introductorio de A. Villar, Madrid, Gredos.

\section{OBRAS SOBRE PASCAL Y OTROS ESTUDIOS}

Albiac, G. (1981). Pascal, Barcelona, Barcanova.

Albiac, G. (1985). "Introducción” a B. Pascal, Pensamietos, Madrid, Espasa-Calpe.

Albiac, G. (2013). Blaise Pascal. La máquina de buscar a Dios (Una antología), Madrid, Tecnos.

Aranguren, J. L. L. (1997). "Prólogo a las Obras de Pascal", en Obras completas, ed. de

F. Blázquez, Madrid, Trotta, 6 vols., vol. 6, 585-613.

Aristóteles (1994). Metafísica, trad. e introd. de T. Calvo, Madrid, Gredos. 
Delumeau, J. (1973). El catolicismo de Lutero a Voltaire, trad. de M. Candel, Barcelona, Labor.

Febvre, L. (1970). Erasmo, la Contrarreforma y el espíritu moderno, Barcelona, Martínez Roca.

Febvre, L. (1975). Martin Lutero: un destino, México, FCE, 3a ed.

Goldmann, L. (1968). El hombre y lo absoluto. Estudios sobre el pensamiento trágico en Pascal y Racine, trad. de J. R. Capella, Barcelona, Península. [ed. orig., Le Dieu caché, 1955].

Gómez, C. (1998). Freud, crítico de la Ilustración, Barcelona, Crítica.

Gómez, C.: (2002). Freud y su obra. Génesis y constitución de la Teoría Psicoanalitica, Madrid, Biblioteca Nueva, 2002 (2a ed., 2009).

Gómez, C. (2007). “Ética y religión”, en C. Gómez y J. Muguerza (eds.), La aventura de la moralidad, Madrid, Alianza. (5a reimpr., 2013).

Kant, I. (1972). Crítica de la razón práctica, trad. de E. Miñana y M. García Morente, México, Porrúa.

Kant, I. (1985). Critica de la razón pura, ed.. de P. Ribas, Madrid, Alfaguara, 4a ed.

Kant, I. (1996). Fundamentación de la metafísica de las costumbres, ed. bilingüe y trad. de J. Mardomingo, Barcelona, Ariel.

Kolakowski, L. (1971). "La trivialidad de Pascal”, en Vigencia y caducidad de las tradiciones cristianas, trad. de R. Bilbao, Buenos Aires, Amorrortu [introducción a la edición alemana de las Cartas Provinciales]

Kolakowski, L. (1996). Dios no nos debe nada. Un breve comentario sobre la religión de Pascal y el espiritu del jansenismo, trad. de S. Mactley Marín, Barcelona, Herder.

Kolakowski, L. (2007). “Gran Enciclopedia de la Filosofía y las Ciencias Sociales”, en ¿Por qué tengo razón en todo?, Santa Cruz de Tenerfie, Melusina.

Mesnard, J. (1973). Pascal. El hombre y su obra, trad. de P. López, Madrid, Tecnos.

Muguerza, J. (1991). “Kant y el sueño de la razón”, en C. Thiebaut, La herencia ética de la Ilustración, Barcelona, Crítica.

Rivera de rosales, J. (2004a). "La moralidad. Hegel versus Kant. I”, en M. Álvarez Gómez y M. C. Paredes Martín, La controversia de Hegel con Kant, Salamanca, ed. Universidad de Salamanca.

Rivera de rosales, J. (2004b). "La moralidad. Hegel versus Kant. II”, Éndoxa, 18, 383-416.

Sófocles (1992): Antígona, en Tragedias, trad. de J. Alamillo, introd. De J. Lasso de la Vega, Madrid, Gredos. 
Trías, E. (1988). Lo bello y lo siniestro, Barcelona, Ariel.

Unamuno, M. De (1966). Vida de Don Quijote y Sancho, Madrid, Círculo de Lectores. KüNG, H. (1979). ¿Existe Dios?, trad. de J. Ma Bravo Navalpotro, Madrid, Cristiandad. Villar, A. (1987). Pascal: ciencia y creencia, Madrid, Cincel.

Villar, A. (2012). "Estudio introductorio” a Pascal, Obras, Madrid, Gredos.

Wittgenstein, L. (1973). Tractatus Logico-Philosophicus, trad. de J. Muñoz e I. Reguera, Madrid, Alianza

Recibido: 3/11/2014

Aceptado: 2/12/2014

Este trabajo se encuentra bajo una licencia de Creative Commons ReconocimientoNoComercial-SinObraDerivada 4.0

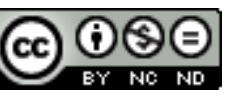

